\title{
Assessment of the Outcome of Acetabulum Fractures by Open Reduction and Internal Fixation
}

\author{
Vipin Tyagi ${ }^{1}$, Amit Dwivedi ${ }^{2 *}$, Rahul Kakran ${ }^{3}$, Shriya Garg ${ }^{4}$ and \\ Robium Naorem ${ }^{5}$ \\ ${ }^{1}$ Senior Consultant, Department of Orthopedics, Yashoda Superspeciality Hospital, \\ Ghaziabad, Uttar Pradesh, India \\ ${ }^{2}$ Professor and HOD, Department of Orthopaedics, Santosh Medical College and \\ Hospital, Ghaziabad, Uttar Pradesh, India \\ ${ }^{3}$ Consultant, Department of Orthopaedics, Yashoda Superspeciality Hospital, \\ Ghaziabad, Uttar Pradesh, India \\ ${ }^{4}$ Junior Resident, Department of Orthopedics, Yashoda Superspeciality Hospital, \\ Ghaziabad, Uttar Pradesh, India \\ ${ }^{5}$ Post Graduate, Department of Orthopaedics, Santosh Medical College and \\ Hospital, Ghaziabad, Uttar Pradesh, India \\ *Corresponding Author: Amit Dwivedi, Professor and HOD, Department of \\ Orthopaedics, Santosh Medical College and Hospital, Ghaziabad, Uttar Pradesh, \\ India. \\ DOI: 10.31080/ASOR.2022.05.0421
}

\begin{abstract}
Introduction: Acetabular fractures are one of the most challenging and complex injuries encountered by the orthopedic surgeons. Because the acetabulum involves a major weight bearing joint in the lower limb, these fractures are of great clinical importance. The main aim in such fracture management is the proper anatomical reduction for the good functioning of the hip joint.

Aims and Objective: In this study, our aim is to assess the outcome of the acetabular fractures operated by open reduction and internal fixation with plating.

Method: In this retrospective study, we included 30 patients with acetabular injuries who needed surgical intervention as per the indications. The patients were selected according to the inclusion and exclusion criteria. The patients were operated between November 2019 to December 2020 at Yashoda Superspeciality Hospital, Nehru Nagar, Ghaziabad.

Result: Follow up of the patients was done at 6, 8 and 12 weeks and 6 and 12 months. The patients were assessed according to the Modified Harris Hip Score.

Out of the 30 patients included in this study, 26 patients had excellent result, 3 patients had good result and 1 patient had fair result who developed stitch line infection which was treated with antibiotics.

Conclusion: All the patients operated had successful outcome with weight bearing, mobilization, and return to normal life and activities of daily living. Ilioinguinal, stoppa approach and KL approach have good outcome and the choice depends on the operating surgeon and the configuration of fracture.
\end{abstract}

Keywords: Acetabulum; Pelvis; Plating; Stoppa Approach; Ilioinguinal Approach; Harris Hip Score

Citation: Amit Dwivedi., et al. "Assessment of the Outcome of Acetabulum Fractures by Open Reduction and Internal Fixation". Acta Scientific Orthopaedics 5.3 (2022): 02-06. 


\section{Introduction}

Acetabular fractures are one of the most challenging and complex injuries encountered by the orthopedic surgeons [1,2]. Because the acetabulum involves a major weight bearing joint in the lower limb, these fractures are of great clinical importance. The main aim in such fracture management is the proper anatomical reduction for the good functioning of the hip joint $[3,4]$. In cases with undisplaced acetabulum fractures and some less severe fractures, closed reduction can be done for achieving the anatomical reduction, but mostly open reduction and stabilizing the acetabulum with internal fixating devices is needed. The most common mechanism of such injuries are road traffic accidents, fall in elderly population, or a direct injury over the acetabulum [5-7]. Earlier such surgeries were less often done due to lack of technology, other associated injuries, or severe comminution as in many cases. But with the advancement in the technology and better fixation devices, such fractures are increasingly stabilized with the internal fixation $[8,9]$.

\section{Aims and Objective}

In this study, our aim is to assess the outcome of the acetabular fractures operated by open reduction and internal fixation with plating. We have used three approaches ilioinguinal, stoppa and KL approach. Also, we have used Modified Harris Hip Score post operatively for functional outcome assessment and return to ADL (activities of daily living).

\section{Method}

In this retrospective study, we included 30 patients with acetabular injuries for surgery. The patients were selected according to the inclusion and exclusion criteria.

- Inclusion criteria- 1. Patients with unilateral or bilateral acetabulum injury. 2. Age $>20$ years. 3. Patients without any comorbidities. 4. Patients who were fit for surgery.

- Exclusion criteria- 1. Polytrauma patients with fracture of other bones. 2. Age $<20$ years. 3. Patients with co-morbidities. 4. Patients unfit for surgery. 5. Patients unwilling for the surgery. 6. Undisplaced fractures stabilized with closed reduction.

The patients were operated between November 2019 to December 2020 at Yashoda Superspeciality Hospital, Nehru Nagar, Ghaziabad.

The patients were operated by ilioinguinal approach or modified Stoppa approach or KL approach as per the surgeon's convenience.

\begin{tabular}{|c|c|c|}
\hline \multirow{4}{*}{ Type A } & A1 & Posterior wall fracture \\
\hline & A2 & Posterior column fracture \\
\hline & A3.1 & Anterior wall fracture \\
\hline & A3.2 & Anterior column fracture \\
\hline \multirow{4}{*}{ Type B } & B1.1 & Transverse fracture \\
\hline & B1.2 & Transverse with posterior wall fracture \\
\hline & B2 & T fracture \\
\hline & B3 & $\begin{array}{l}\text { Anterior column with posterior transverse } \\
\text { fracture }\end{array}$ \\
\hline \multirow{3}{*}{ Type C } & C1 & $\begin{array}{l}\text { Both column with fracture extending to } \\
\text { iliac crest }\end{array}$ \\
\hline & $\mathrm{C} 2$ & $\begin{array}{l}\text { Anterior column extends to anterior } \\
\text { inferior iliac spine }\end{array}$ \\
\hline & C3 & $\begin{array}{l}\text { Both column with fracture extending to the } \\
\text { sacroiliac joint }\end{array}$ \\
\hline
\end{tabular}

Table 1: AO classification for acetabulum fractures.

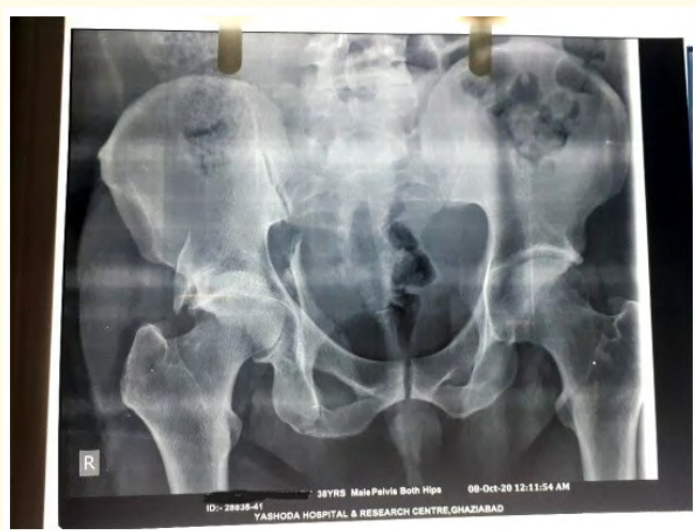

Figure 1A: Pre-Op X-ray of a 38-year-old male with right acetabulum fracture.

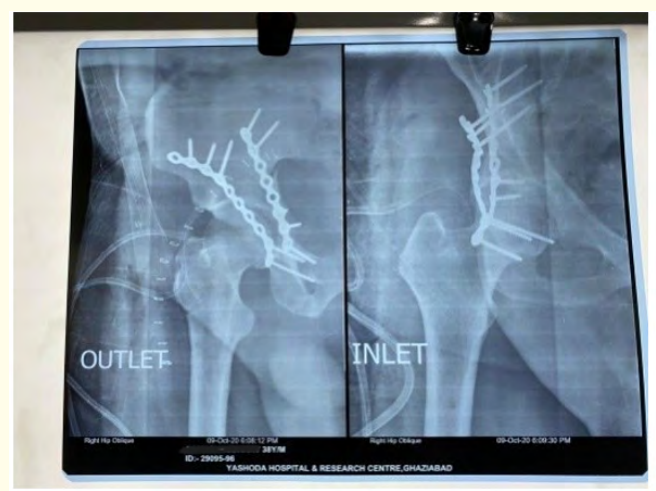

Figure 1B: Post Op Xray of a 38-years-old male with Open reduction with plating. 


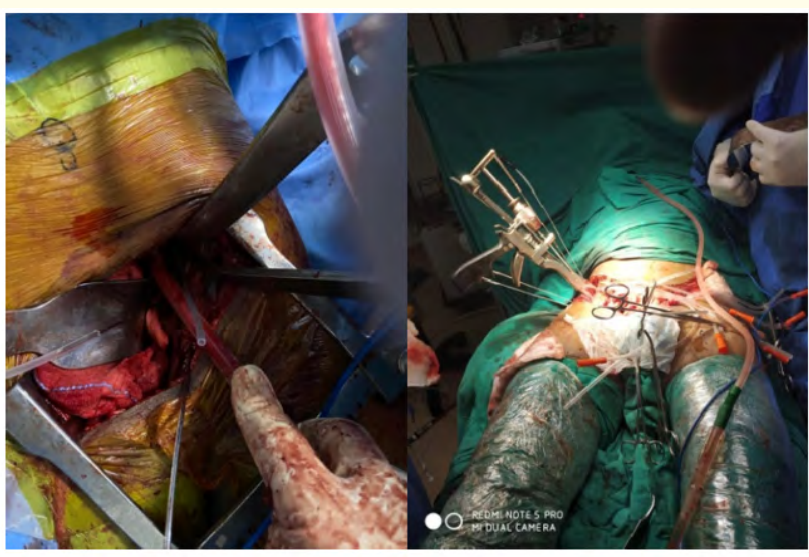

Figure 1C: Intra Op Xray using stoppa approach.

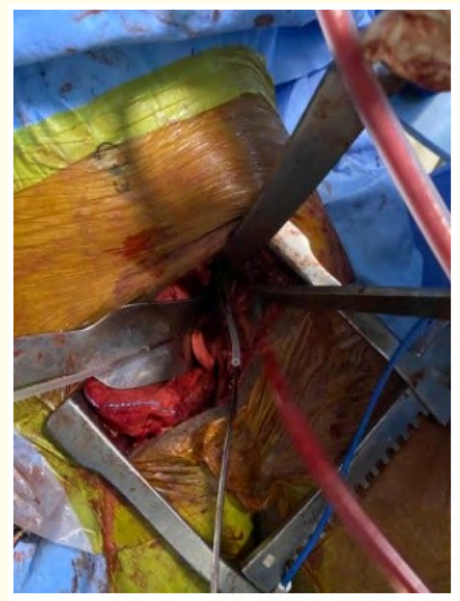

Figure 1D: Intraoperative images of 38 years male patient with acetabular fracture of right side managed by ORIF with platting.

\section{Result}

- Follow up of the patients was done at 6, 8 and 12 weeks and 6 and 12 months. No weight bearing was done up to 6 weeks.

- $\quad$ Partial weight bearing was done between 6 to 8 weeks. Full weight bearing was started from $12^{\text {th }}$ week.

- $\quad$ The patients were assessed according to the Modified Harris Hip Score.

- $\quad$ Out of the 30 patients included in this study, 26 patients had excellent result, 3 patients had good result and 1 patient had fair result who developed stitch line infection which was treated with antibiotics.

\begin{tabular}{|l|c|}
\hline Modified harris hip score & No of patients \\
\hline Excellent & 26 \\
\hline Good & 3 \\
\hline Fair & 1 \\
\hline Poor & 0 \\
\hline
\end{tabular}

Table 2: Number of patients according to modified harris hip score ${ }^{1}$.

(Result based on performance of post operative patients as per the Modified Harris Hip Score).

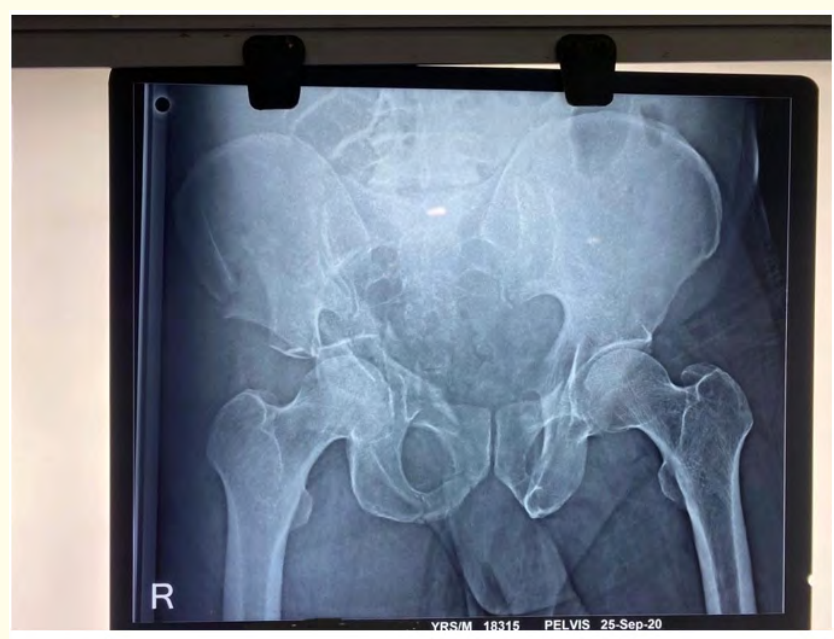

Figure 2A: Pre op X-ray of a 63 years old male with acetabulum fractures.

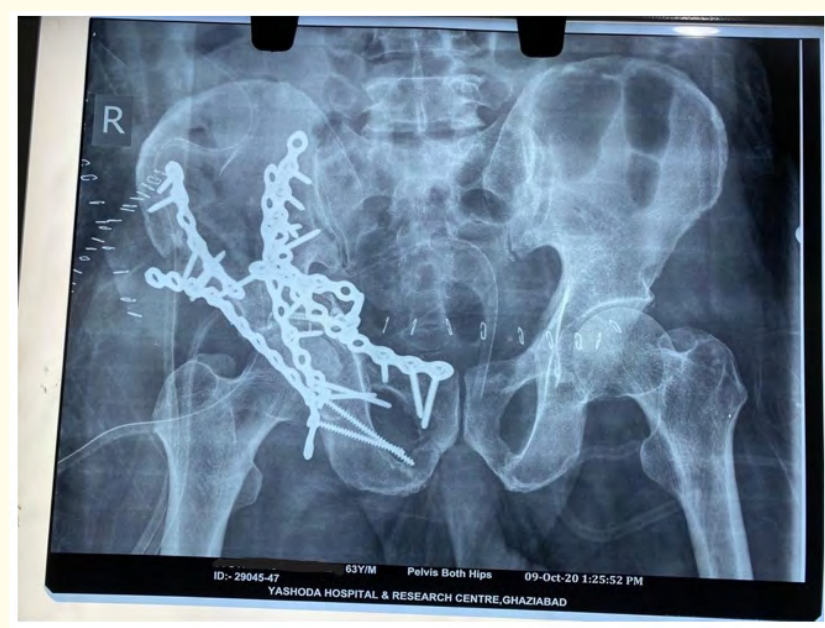

Figure 2B: Post-op X-ray of a 63 years old male managed by ORIF with Plating.

Citation: Amit Dwivedi., et al. "Assessment of the Outcome of Acetabulum Fractures by Open Reduction and Internal Fixation". Acta Scientific Orthopaedics 5.3 (2022): 02-06. 


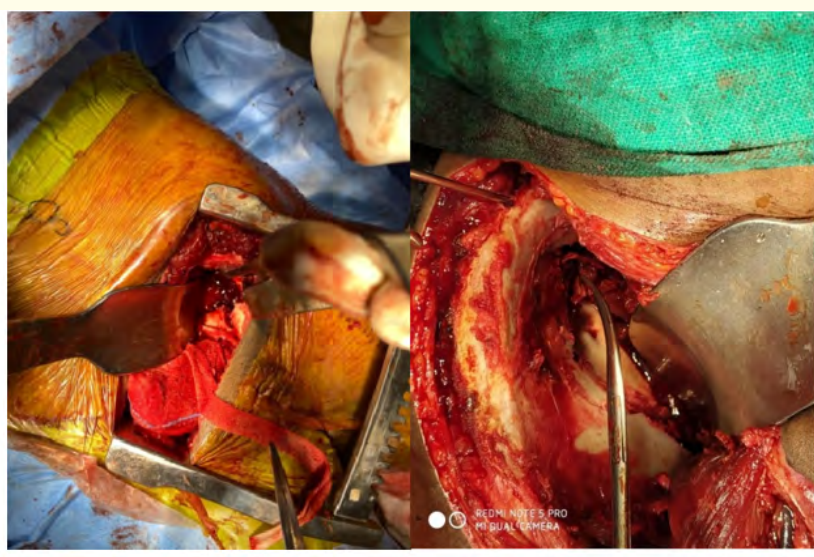

Figure 2C: Intra operative images of 63-years male patient with right side acetabulum fracture.

\section{Discussion}

Acetabular fractures are one of the most challenging and complex injuries encountered by the orthopedic surgeons. The main aim in such fracture is the proper anatomical reduction for the good functioning of the hip joint. The most common mechanism of such injuries are road traffic accidents, fall in elderly population, or a direct injury over the acetabulum. Earlier such surgeries were less often done due to lack of technology, other associated injuries, or severe comminution as in many cases. But with the advancement in the technology and better fixation devices, such fractures are increasingly stabilized with the internal fixation $[11,12]$.

The advantage of the stoppa approach is that it is a time sparing approach, better visualization of the neurovascular bundles, easy access to both the pelvis and acetabulum, less complications and less wound drainage while disadvantage is tension on the femoral vessels while retracting the anterior abdominal wall, damage to peritoneum while reduction, two experienced orthopedic surgeons are needed for the surgery.

The advantage of the ilioinguinal approach is that entire internal iliac fossa can be assessed. Disadvantage is that it is time consuming, more complications, it needs three windows, damage to the femoral vessels and more wound drainage.

In this study, we included 30 patients who were having acetabulum injury, mode of injury in most of the cases was road traffic accidents and trauma. The patients were operated using the stoppa approach, the ilioinguinal approach and KL approach, the decision was according to the operating surgeon.

Blood loss during the intraoperative period in the patients operated by ilioinguinal approach was $1175 \pm 100 \mathrm{ml}$ while in patients operated by stoppa approach was $1010 \pm 100 \mathrm{ml}$. the less blood loss in stoppa approach might be because of shorter operative period and less wound drainage.

We assessed the patients according to the Modified Harris Hip Score had no significant difference in the approaches. Final radiological results and the quality of reduction in stoppa approach were found to be better than in those with ilioinguinal approach. Cancellous bone grafting and reduction without dislocating the joint must be the reason for the better radiological results with the stoppa approach [13].

One patient, who was operated with ilioinguinal approach developed suture line infection, which was managed by the antibiotics. The patients follow up was done at 6,8 and 12 weeks and 6 and 12 months.

Our study concludes that either of the approach could be used for the acetabulum fractures as per the convenience of the operating surgeon.

\section{Conclusion}

All the patients operated had successful outcome with weight bearing, mobilization, and return to normal life and ADL (activities of daily living). The approaches, ilioinguinal and stoppa approach, KL approach have good outcome and the choice depends on the operating surgeon and the type and pattern of fracture. Blood loss was less in Stoppa approach and might be due to short operative time and less wound drainage.

\section{Conflict of Interest Statement}

On behalf of all authors, the corresponding author states that there is no conflict of interest.

\section{Bibliography}

1. Judet R., et al. "Fractures of the acetabulum: classification and surgical approaches for open reduction: preliminary report". Journal of Bone and Joint Surgery Am 46 (1994): 1615-1646. 
2. Matta JM and Merritt PO. "Displaced acetabular fractures". Clinical Orthopaedics and Related Research 230 (1988): 83-97.

3. Ali E. "Acetabular Fractures - A Review of their Management". Journal of Trauma and Treatment 4 (2015): 1-5.

4. Tile M., et al. "Fractures of the Pelvis and Acetabulum". (Lippincott Williams and Wilkins, 2003).

5. Tile M. "Fractures of the acetabulum". Orthopedic Clinics of North America 11 (1980): 481-506.

6. Liebergall M., et al. "Acetabular fractures. Clinical outcome of surgical treatment". Clinical Orthopaedics and Related Research 366 (1999): 205-216.

7. Letournel E. "Acetabulum fractures: classification and management". Clinical Orthopaedics 151 (1980): 81-106.

8. Giannoudis PV., et al. "Operative treatment of displaced fractures of the acetabulum, a meta-analysis". Journal of Bone and Joint Surgery Br. 87 (2005): 24-29.

9. Carroll EA., et al. "Treatment of acetabular fractures in an older population". Journal of Orthopaedic Trauma 24.10 (2010): 637-644.

10. Mahomed N N., et al. "The Harris hip score: comparison of patient self-report with surgeon assessment". Journal of Arthroplasty 16 (2001): 575-580.

11. Hodgson S. "AO Principles of Fracture Management". Annals of The Royal College of Surgeons of England 91 (2009): 448-449.

12. Matta JM. "Operative indications and choice of surgical approach for fractures of the acetabulum". Techniques in Orthopaedics 1.1 (1986): 13-22.

13. Rowe CR and Lowell JD. "Prognosis of fractures of the acetabulum". Journal of Bone and Joint Surgery Am 43-A (1961): 30-59.

\section{Assets from publication with us}

- Prompt Acknowledgement after receiving the article

- Thorough Double blinded peer review

- Rapid Publication

- Issue of Publication Certificate

- High visibility of your Published work

Website: www.actascientific.com/

Submit Article: www.actascientific.com/submission.php

Email us: editor@actascientific.com

Contact us: +919182824667 